\title{
Random display and recommendations - exploring the web platform of the artist Ivar Arosenius and other digital collections of art
}

\author{
Karin Wagner
}

\begin{abstract}
This article takes as its point of departure a web platform intended to bring forward the lifeworks of artists and enable new ways of combining, comparing and considering their works. The focus is on three features of the platform, also used by many prominent art museums: random display, recommendations and $\mathrm{Al}$ powered visual similarity search. The purpose of the article is to critically analyze these features and put them in a broader cultural and commercial perspective. What possibilites do these features offer and what pitfalls might they entail? In what way could these features contribute to challenging or consolidating the art history canon? New technology can be deployed to increase accessibility to collections, but as long as the rhetoric of traditional art history resides on art museums websites, it will be hard to alter the canon.
\end{abstract}

Key words: generous interfaces; canon; random display; recommendations; visual similarity search

\section{Introduction}

Digitization of art collections mostly focus on institutions, not on single artists. In meta-archives like Europeana, where many European cultural heritage institutions contribute their digital content, searching for individual artists is possible, but such searches seldom render the complete picture. If one wishes to get an overview of the lifework of an artist, one may have to visit all the websites of the institutions which hold artworks and archival material by the artist in question. In the project Conjuring Up the Artist from the Archive: The Case of Ivar Arosenius (2016-2019) the main idea was to achieve such an overview by creating a platform that makes the artist's well-known works, as well as his lesser-known works and sketches, letters, notebooks, family photographs, press cuttings, and similar material, accessible to scholars, students and the general public. This platform, and above all the experience drawn from its development, is intended to bring out the lifeworks of other artists and enable new ways of combining, comparing and considering their works.

The artist Ivar Arosenius was born in Gothenburg, Sweden, in 1878 and died a premature death due to haemophilia in 1909. His oeuvre is multifaceted, characterized by fantasy, humour and satire as well as melancholy and thoughts on death. He became famous for his paintings, but also for the children's book The Cat Journey, which has been read by generations of children. A large part of his oeuvre is in the collections of the Nationalmuseum in Stockholm and of the Göteborgs Konstmuseum, which own about 200 works each. The archival material is held by the Gothenburg University Library and by the Nationalmuseum. These institutions are the main partners in the project. Calls for private owners to share images of their works have resulted in an additional 200 images, which means the platform now contains a larger collection of images of Arosenius' work than has ever been available.

Previous research related to the Arosenius archive examined affective aspects of the archival material in an exhibition context (Herlitz and Westin 2018); and investigated how a digital reconstruction of Arosenius' last home could serve as an entrance to the archive and connect artworks and documents to the places where he lived and worked (Westin and 
Claésson 2017). The purpose of this article is to critically analyze some of the features for display and comparison used by the Arosenius platform and put them in a broader cultural and commercial perspective. The features in focus are:

- random display

- recommendations

- Al-powered visual similarity search.

Such features are also used by web projects such as Europeana and Google Arts \& Culture, which aggregate digital museum collections, and by some prominent art museums' websites, which have served as reference material in the study.

The key questions that have guided my inquiry are: What possibilities do these features offer and what pitfalls might they entail? In what way could these features contribute to challenging or consolidating the art history canon? New technology is often surrounded by hype and sometimes widely adopted as solutions to complex problems, solutions that deserve to be examined and viewed from different perspectives.

The study differs from visitor and user studies, performed with the intention of improving the design of museum websites (Ardissono et al. 2012; Villaespesa 2019), in that it does not offer an assessment of websites from a usability perspective, and it does not involve user testing or surveys with users. I have analyzed the three features in focus from the position of an expert, in my double capacity as art historian and systems analyst, which gives me a twofold perspective on the issue of the influence of information technology on the historiography of art. With the Arosenius platform as a point of departure, I have chosen four renowned museums that are at the forefront of digitization as reference sites: the National Gallery and Tate in London, the Rijksmuseum in Amsterdam, and the Metropolitan Museum in New York, as well as two major web projects: Europeana and Google Arts \& Culture, mentioned above. (A number of famous museums were omitted on the basis that their websites lack the features relevant for this study.) I have also used the websites of the companies Amazon, Zalando and Taylor \& Francis as reference regarding the comparison between cultural heritage and e-commerce sites. Multi-modal discourse analysis has been used as methodological framework, in order to capture how the technical, visual and textual elements interact to create the rhetorical framing of the sites (Kress and van Leeuwen 1996; Ledin and Machin 2018). The main method used in the study has been an iterative analysis of the selected websites, which aimed to observe the websites' interfaces, features, and search possibilities.

\section{Arranging images}

The question of accessibility of art, technologies of reproduction and of the organization of images did not arise with digitization. The German art historian Aby Warburg's Mnemosyne Atlas, begun in 1924, implied a pioneering approach to mapping out history through the arrangement of images from a broad range of contexts (Warburg et al. 2000). ${ }^{1}$ His interest was the afterlife of antiquity, but his method, which constitutes his main legacy, is applicable to other periods and areas. The atlas was based on photographs and printed images from newspapers and magazines that Warburg pinned to large, wooden panels in his library. This allowed him to get an overview of the images and arrange and rearrange them (Schuller 2011; Finch 2016). Photography was vital to Warburg's project. This technology also played a major role for the French art theorist André Malraux in his conceptualization of the imaginary museum. In Museum Without Walls he argues that photographic reproductions have not only increased the accessibility of artworks, but also entailed more penetrating insights into, and broader exploration of, art (Malraux 1967). Before, engravings were made only of masterpieces, whereas after the diffusion of photography minor arts and works of unknown artists were being reproduced. This led to a new perception of what constitutes a masterpiece - the typical work superseded the ideal masterpiece (Malraux 1967). Art books with photographic reproductions enabled stylistic analysis of art based on a much richer source material than was previously available to the art connoisseur, who travelled between 
the sites and could only access a small part of all existing art. According to Malraux, black and white photography, which was the dominant reproduction method at the time, had the advantage of bringing works closer to each other and making comparison easier, since the works lose their colour, scale and materiality. By means of enlargement, fragments could be isolated and highlighted. For Malraux, photography was therefore instrumental to a more intellectual approach to art history (Malraux 1967).

In the digital age, the media theorist Lev Manovich has taken Malraux's ideas further and created visualizations based on the processing of huge amounts of data from the field of art and visual culture (Manovich 2013, 2017). Using software developed at his Cultural Analytics Lab, he has compared the paintings made by van Gogh in Paris and Arles, with respect to stylistic aspects such as brightness and saturation (Manovich 2015). When photography began to be used on a mass scale in social media, Manovich conducted projects such as 'Selfiecity', which discusses the content and style in photographs shared in a global context. ${ }^{2}$ In 1996, at the dawn of the World Wide Web, the art historian Hal Foster put forward the question of how long it would take before we understand the epistemological implications of digital technology for the field of visual culture. In the article 'The Archive without Museums' he expressed concern that an inhuman digital logic would prevail to the detriment of the autonomy of art and images.

If, according to Malraux, the museum guarantees the status of art and photographic reproduction permits the affinities of style, what might a digital reordering underwrite? Art as image-text, as info-pixel? An archive without museums? If so, will this database be more than a base of data, a repository of the given? (Foster 1996: 109)

Manovich's projects have proved this prediction unwarranted, mainly because the whole image ecology has been transformed by digitization. It is not just a means of reproduction, storing and sorting of images. The digital age has entailed a different way of producing images and new contexts of sharing images, which have implications for the reception and dissemination of older art collections as well.

\section{Generous interfaces}

By groupwise comparison of images, Warburg, Malraux and Manovich were all searching for something: for the afterlife of antiquity, for the style of an epoch, for the typical selfie. What about having no particular idea of what to search for? Interface developers need to be involved in the work necessary to make a digitized museum collection or an artist's platform accessible to a larger audience (Whitelaw 2015). The users will not only be experienced art historians, but also people who are only slightly acquainted with the works or have no previous knowledge of the artist at all. The approach used in the Arosenius archive is called generous interfaces, which means that a text-based search query is not the only way to enter the archive. On the initial screen, part of the content will be displayed so that the user can start exploring the archive by clicking on an object and then go further. According to Whitelaw, a generous interface is characterized by the following steps:

- Show first, don't ask (provide rich overviews without search)

- Provide samples and clues (using collection content)

- Show relationships (between collection features)

- Provide rich primary content (deliver on the promise). ${ }^{3}$

This strategy, to introduce the user/viewer to the collection by showing an overview of it, is similar to the strategy often used by filmmakers who introduce viewers to a film by showing an establishing shot. Such long shots present the scene where the story will take place and help the viewers orient themselves in the terrain of the film. The generous interface gives the archive explorer a similar opportunity to get acquainted with the archive. A research project exploring the potential of generous interfaces was carried out in Tyne \& Wear Archives \& 
Museums, Great Britain, during 2014-2015. The findings show that there is a large audience that would like to engage with the collection without having a specific query, and that for some users, 'the collections interface was an holistic experience and an encounter with a rich collage of juxtaposed artefacts'. ${ }^{4}$

\section{The Arosenius archive}

The web interface of the Arosenius archive is designed to serve users with different backgrounds and knowledge about the artist. ${ }^{5} \mathrm{~A}$ search box is in the centre of the screen and, below, a gallery of thumbnails is shown in random order. By continuing to scroll down, one could eventually see the entire collection. The thumbnails show first the artworks, then the photographs and finally the documents. No metadata is shown, only the objects themselves are displayed. This Gallery mode is the default mode, and other options for browsing the collection include a timeline and a catalogue view, where textual information, derived from the metadata, is shown near the objects. The metadata was compiled from the collection databases of the partner institutions, where it had been manually encoded.

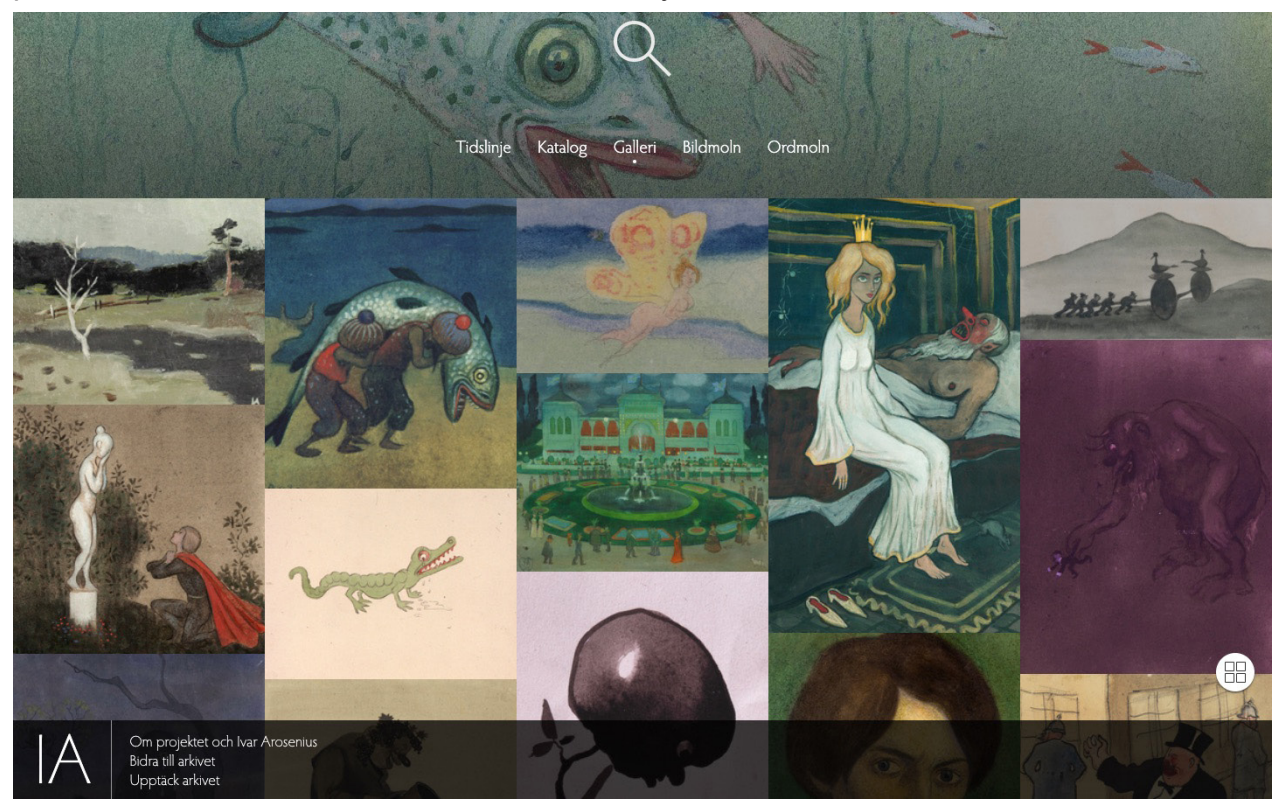

Figure 1. Initial screen of the Arosenius archive with a random sample of works

I will demonstrate how the exploration of the archive works by starting with an example of the initial screen, which shows a random selection of works (Figure 1). From these I pick The Princess at the Troll's, which shows a sombre looking young girl sitting on the bed of an old man with a grotesque red nose and mouth, fast asleep and seemingly snoring. In the single picture mode, a title and a description are provided, along with metadata such as size, material and tags (Figure 2). The image can be enlarged, rotated and downloaded. When enlarging the image, the viewer might discover the spider web hanging from the ceiling, and the rat on the floor, details that may otherwise have been overlooked. Below the image, a mini gallery of similar images is suggested, similar with regards to colour scheme and structure (Figure 3). Many of the suggested images contain two persons, some a group of people and some just one person. Other mini galleries follow, based on the tags for this painting (troll, princess, dress, interior, spider, rat), and finally works made in the same medium (painting) and works belonging to the same institution (Göteborgs Konstmuseum). The suggestions based on tags group images according to motifs and could be said to reflect an iconographic perspective on art. 


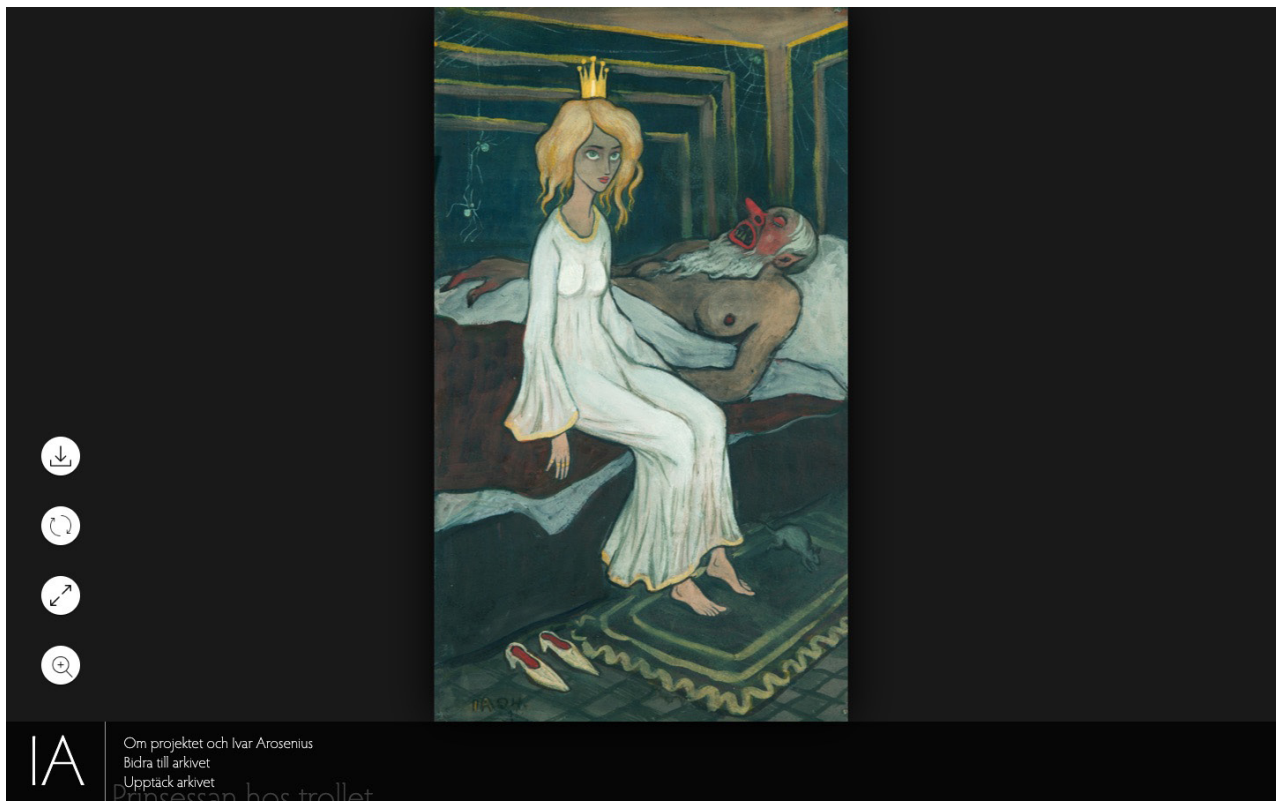

Figure 2. Single picture chosen from the initial screen

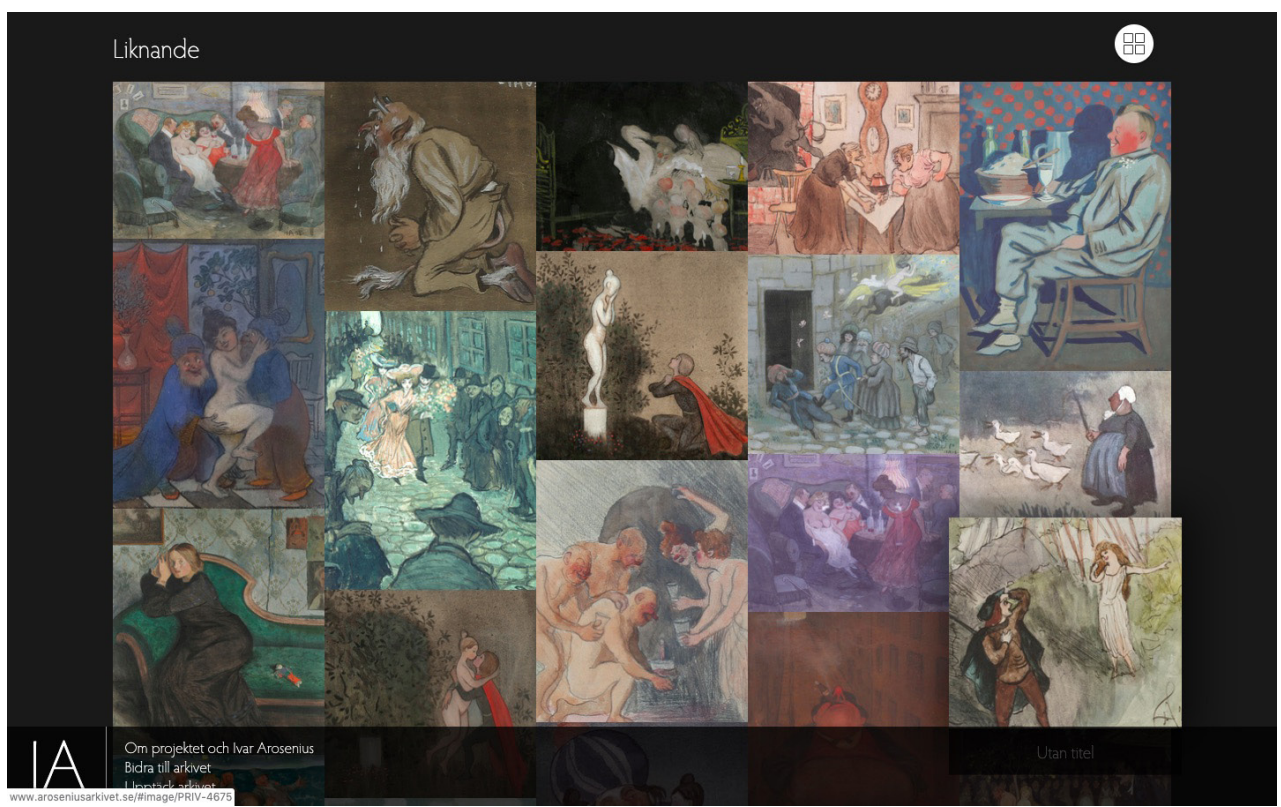

Figure 3. Mini gallery with similar works

Foster feared that the advent of art history databases would entail a slant towards the iconographic perspective on art, which he somewhat sarcastically called the Revenge of Iconography. 'One can imagine the dissertation subjects: lemons in seventeenth-century Dutch still life, dogs in art, dicks in Twombly' (Foster 1996: 112). I cannot say to what extent digitization has led to a revenge of iconography within art historical research, but iconography 
certainly assumes a central position in the tagging approach within online collections and is one of the more evident paths opened up for exploration. For novice Arosenius explorers, such searches can be rewarding. One does not have to browse the archive for a long time before noticing how hats are used by Arosenius to give character to persons, not least to himself. In many of his self-portraits, for instance Self-Portrait with Pigs and Hens, he is seen wearing his signature hat, a pointed felt hat that contributed to his bohemian appearance. Some of his friends can also be recognized by their headgear, for instance the flat hat of the artist Gerhard Henning. On a more conventional note, Arosenius used the top hat to designate capitalists and male members of the bourgeoisie in his satirical works, criticizing the morals of the time. This example shows how the generous interface can work in concordance with the search box, how giving a visual overview can lead to finding relevant search terms, an iterative process that can go on for many turns. 'The hat', 'the troll', or 'the princess' are not necessarily ends in themselves, but can serve as the starting points of finding more complex themes in the artist's oeuvre, such as criticism of society or gender relations.

\section{Serendipity, the canon and the rhetoric of the masterpiece}

The display of artworks in exhibitions and in books are rarely based on a random selection, but is normally the result of curating and editing. When entering an exhibition space, the first thing that meets the eye of the visitors is usually a curatorial statement, which outlines the purpose and concept of the exhibition. This will guide the visitors through the exhibition and help them find the main thread when moving around in the gallery. At the same time, although the physical architecture highly influences the way visitors can experience an exhibition, most spaces do not force them to follow a certain path, but allow them a certain degree of freedom. Visitors can choose to see the artworks in a different order than intended, to skip certain works and stay longer in front of some works than others.

Similar conditions exist in other contexts of society. In the retail trade, shop visitors are also influenced by underlying ordering principles. Clothes in a fashion shop, vegetables in a market stall, books in the library, most things we encounter in everyday life are displayed in some kind of order to facilitate selection, maybe with the exception of jumble sales. To make purchases online, consumers have to navigate databases with goods where they can filter and sort with the help of multiple criteria. The software systems used in online galleries of art and online shops are similar in this respect.

Serendipity is consequently not the default ordering principle in most contexts, so why would it be an advantage in the context of art archives and collections? Because order is not just a practical way of organizing things, order also comes with judgements and values. In the clothing industry, what counts is the latest fashion. In art history, it is the canon. The aim of using random display for online collections is to invite the viewer to engage in an unprejudiced exploration of the archives, unhampered by the shackles of the canon. Art history, as well as the other aesthetic disciplines, has seen as its task to sort out the wheat from the chaff, designating geniuses and masterpieces. Works by the masters constituted the canon that educated citizens should know and other artists follow as an ideal (Sanderhoff 2017).

Much criticism has been directed towards the canon as an obsolete phenomenon with a strong Western bias, but the canon still exerts influence and continues to form the basis for exhibitions and text books (Brzyski 2007; Warbelow 2013; Langfeld 2018). Giving users open access to vast digital collections enables them to 'question the canon by the very act of clicking outside the mainstream' (Sanderhoff 2017: 217).

Only a minor part of Arosenius' oeuvre has been made public by exhibitions and publications, as is the case with many artists. A small number of his works are on permanent display in museums in Sweden. The Arosenius archive gives users access to digital representations of all his known works, both privately and publicly owned, and to photographs and archival documents. This extended access makes it possible for researchers to view his oeuvre in a new light, which could lead to historiographic reassessments of Arosenius' life and work. The archive is also accessible to the general public, who might make new discoveries on their own among works hitherto unknown or kept in storerooms of museums. The images in the Arosenius archive are in the public domain and can be downloaded and published 
in other contexts than the archive itself. The established Arosenius canon, reiterated in art history books, exhibitions and museum displays, has only encompassed a few of his works. The greater exposure of Arosenius' work in combination with the fact that researchers and the general public have simultaneous access to his work, could potentially lead to a shift of the established Arosenius canon, adding new works to it, or replacing old ones. This could happen through scholarly publications as well as through blogs and other web based forms of publications to which the general public has access.

Random display can help challenge the canon because this display method refrains from privileging the 'best' or the best known work in the order of display. With this method, it might happen that, for instance, Arosenius' famous self-portrait with a flower wreath will be among the last works to be presented, instead of the among the first, which would have been more likely according to the logic of the prevailing canon. However, random display can also be used to confirm the canon, as the following example from the National Gallery in London shows. Visitors of the National Gallery's website are given the following options to view the collection: 'Artist A to Z, Browse by century, 30 must-see paintings, Latest arrivals, Take a chance!' When clicking on the last option, the following text appears:

'Take a chance!

Congratulations. You have generated a random search of the collection, pulling out just 10 of our masterpieces. Hit Take a Chance! again to discover further surprises'. ${ }^{6}$

The rhetoric is reminiscent of a lottery advertisement, appealing to people's inclination for gaming. Positive words like congratulations, chance, and surprise are used to assure users that they do not risk encountering a minor work, normally hidden in the back of the museum storeroom. Although randomly retrieved, it will still be a masterpiece - a winning ticket, not a losing ticket. Rijksmuseum uses a similar rhetoric, 'Discover the possibilities of the masterpieces' when encouraging users to explore the possibilities of the Rijksstudio, where people can create their own collections.

In the Arosenius archive, all kinds of works are shown side by side: mature works, paper figures he made as a child, academy drawings of Roman portrait sculptures, New Year cards, illustrated letters etc. These random samples are not accompanied by any text or comment, which is a conscious decision taken by the design team in order to let the images speak for themselves. ${ }^{7}$ In his Mnemosyne project, Warburg refrained from 'interpretive text: he merely indicated the common tropes in visual art, regardless of their spatio-temporal specificities, through photographic reproductions' (Becker 2013: 5). In the random display of the Arosenius archive, no common tropes are indicated; it is up to the user to discover common traits, patterns, or just single works of interest, in the broad scope and diversity of Arosenius' lifework. If there was an 'answer' hidden in plain view on Warburg's panels, no such key is intentionally located in the random display.

\section{The kaleidoscope}

The National Gallery displays ten works at a time, and encourages the user to reload the page to see another set of works. The Arosenius archive also generates a new random selection when re-entered. One of the main features of these two websites, as well as of other websites using randomized presentation, is the flexibility, the renewability of the selection. An analogue precursor would be the kaleidoscope, which yields new random constellations each time one shakes the objects or rotates the object chamber. Flexibility was also a characteristic of Warburg's Mnemosyne project. Its material execution depended on plain wooden panels covered in black cloth, on which the pictures were fastened with pins. In this way, the picture could be easily moved, in order to create new permutations, new constellations of pictures, opening up new perspectives on the afterlife of antiquity. The simple technique of the pin facilitated the reconfiguration of images (Schuller 2011).

An important difference between the generous interfaces with random display and the Mnemosyne Atlas is that Warburg's selection process was not random, as mentioned 
above. He decided what pictures to put together, and a second important difference is that his source was not a rather well-defined collection such as Arosenius', but the vast amount of reproductions circulating in printed media. Art historian Colleen Becker highlights the performative aspect of the Mnemosyne project: 'Rather than publish this work, he presented his findings live, in conversations and talks to select audiences. Its format and usage guaranteed that it would remain a continually renewed, rather than finalized, project' (Becker 2013). One can even suggest that had Warburg lived today, these live presentations would perhaps have been published on video-sharing websites or as podcasts. At the heart of his method was the potential for change, which is why it has proven to be so versatile, far beyond its original context. Despite the differences, the renewable, random displays of the generous interfaces pay tribute to Warburg's work and his idea of the flexible, visual assemblage as a means of gaining new insights into art and visual culture.

\section{'You might like' - recommendations and similarity}

From the initial screen with random display, the user is supposed to continue and take a closer look at different objects in a collection. In the Arosenius archive, when the user has selected one of the displayed works and been able to scrutinize it in different degrees of magnification, the system invites the user to further exploration by suggesting similar objects. Both metadata (tags) and visual similarity are taken into account. Such recommendations are given irrespective of the method used to find the object in the first place, whether by random display or through a search query. For instance, when searching the collection of the Metropolitan Museum, inspecting a 'Sword Cane with Scabbard', and scrolling down to the heading 'Related objects', one finds a dagger, a sabre and a hunting sword with scabbard. ${ }^{8}$ Other cultural heritage sites have similar functions. Europeana lists 'Similar items' below 'Suggested content'; Google Arts \& Culture uses 'Additional items', 'Recommended'; Tate uses the phrase 'You might like'. ${ }^{9}$ In all these examples, the recommendations are based on metadata; only Google Arts \& Culture recommends objects both on the basis of metadata similarity and visual similarity. The quality and structure of metadata is thus of vital importance for the search function's ability to guide visitors through the collection. ${ }^{10}$ Furthermore, the headings used on the object pages are interesting from a discourse perspective. The presumption in the Tate case is that the user is looking for art that is likeable - the possibility that the user is looking for art that is repulsive is not taken into account. Researchers, for instance, do not always perform research on art they like. The choice of phrasing may also be influenced by the rhetoric of e-commerce sites, where this phrase occurs frequently. It is another case in point regarding the connection between the software systems used in the commercial sector and the cultural heritage sector.

Addressing the user directly is also a rhetorical device used by the fashion company Zalando, which asks the question 'How about these?'11 In e-commerce websites, product recommendations have long been a standard feature, often based on purchase history and sales statistics, for instance Amazon's 'Customers who bought this item also bought' and academic publisher Taylor \& Francis' 'People also read'. ${ }^{12}$ Product recommendations thus rest on the assumption that we are affected by other peoples' choices, especially people with whom we share similarities. This type of recommender system is called collaborative filtering (Golbeck 2013; Jing and Liu 2013; Kim et al. 2017). Most suggestions in the cultural heritage sector are based on similarity of tags (metadata) and in some cases visual similarity, assuming that we want to see more items like the ones we just picked. Visual similarity is determined by machine learning algorithms, an area of artificial intelligence, which means that similarity can sometimes be detected where no other relation exists. Such systems can be good at 'discovering relatedness based on similarity, but they perform weaker in discovering relatedness based on association. ${ }^{13}$ In a computer vision and machine learning project conducted at the National Museum in Oslo, two rocks on the bank of the fjord in the painting Bridal Procession on the Hardangerfjord (Tidemand and Gude, 1848) were interpreted by the algorithm as 'Asian crocodile' and 'Alligator snapping turtle'.14 This example shows that context is vital when basing recommendations on machine learning.

The question that needs to be asked is: do we desire similarity? A customer visiting an online fashion shop might want to see a similar pair of shoes, but why would a person 
interested in art want to see more of the same? It is really hard to predict what the user would like to see next, which could just as well be something totally different instead of something similar. However, turning away from similarity would lead to a very vague terrain and back to the starting point, the random display. The solution of the Arosenius archive is to suggest a number of mini galleries with visually similar images, then related images based on tags and finally images of the same medium and the same affiliation. In this way, the user has been given several options to go deeper into the archive.

\section{From 'You might like' to 'You will like'}

Although it is possible for the human eye to perceive visual similarity in suggestions based on machine learning algorithms, there are also cases generated by the software that make less sense to humans. There is a discrepancy between how humans and machines process visual information. Humans can quickly see perceptual wholes, or Gestalts, as they are called in gestalt psychology, a branch of psychology developed in the 1920s which focus on a number of 'Gestalt laws' (Poljac et al. 2012). In an experiment using machine learning, which is based on statistical analysis of huge datasets, Kim et al. 2019. showed that machines can also perceive objects according to one of the Gestalt laws, the law of closure, although using a different approach than humans. ${ }^{15}$ The law of closure means perceiving incomplete objects as complete, even when a part of the object is missing, for instance when reading an old typewriter text with ragged letters. There are several other Gestalt laws, for instance the law of similarity, which means we tend to see similar objects as grouped together (Wertheimer 1938). Of special interest for the context of this article is the law of proximity, which means we tend to see objects that are near to each other as belonging together. When being presented with a group of images, even if we know they are a random sample, we might try to find things that these images have in common, looking for how the pieces fit together as in a jigsaw puzzle. Malraux pointed out that when photographed and reproduced on the same book page, even disparate objects with no proper connection can appear as related (Malraux 1967).

Random displays can lead to new discoveries, but there is also a danger that we begin to see contrived connections. Will we come to adopt the machines' notion of similarity or relatedness? In a study on recommendations for music consumers, carried out as laboratory experiments, participants were asked how much they would pay for a song and were presented, first with randomly generated ratings, and subsequently with ratings that had been generated by an algorithm where random errors had been introduced. In both cases, the participants were led to believe the ratings were based on their preferences of past songs. They could listen to the music if they wanted. In the third experiment, listening to the song was mandatory. It turned out that in all three cases, the participants were willing to pay a higher price for a song with a higher rating. The study 'shows that recommendations do more than just reflect consumer preferences - they actually shape them' (Adomavicius et al. 2019: 13). The participants asked themselves not whether they liked a song, but if they ought to like it. All recommendation systems contain errors, and so does the machine learning system generating 'similar' images in the Arosenius archive. When the system suggests that a group of images is similar to the image we just looked at, we will most likely try to find such similarities, even if they might be far-fetched and lead to a dead end.

Google Arts \& Culture has a section for experiments, where people can contribute their applications and have them showcased on the website. One such application is ' $X$ Degrees of Separation', a visualization experiment that analyzes visual features of artworks. The user chooses two artworks as start and end points, then the application finds a pathway between them, consisting of several artworks, getting closer step by step to the appearance at the end point. 'This network of connected artworks allows X Degrees of Separation to take us on the scenic route where serendipity is waiting at every step: surprising connections, masterful works by unknown artists or the hidden beauty of mundane objects'.16 In this case, similarity does not have to be detected by the user; on the contrary, the whole point of the 'game' is to allow oneself to become surprised. The purpose is also to challenge the canon, by letting the user discover 'masterful works by unknown artists'. The rhetoric of masterpieces is not abandoned, only expanded to include more works. 


\section{The digital collection, the canon and user engagement}

Random display is seldom practised in physical art museums, where rooms are organized according to the canon of historical periods, national schools or donors' collections. ${ }^{17}$ This is the traditional art historical organization, which is also mirrored in museum websites using such categories as filter options. The division in periods and styles is knowledge imparted to art history students, like a mental model necessary for orientation in the vast history of art. The canon is a tool, not only for assigning value, but also for narrowing art history down and making it easier to grasp. Digital collections and the ambition to let visitors explore more of the collections work in the opposite direction, by expanding the number of eligible pieces to be included in the canon. In an address to the annual College Art Association meetings in 2006, art historian John Paoletti noted that in their ambition to become more inclusive, textbooks for introductory art history courses are increasing in size, to the point where they become too heavy and too expensive for students. He posed the question, 'by including more and more images, do we run the risk of appearing simply to be enlarging the canon rather than questioning it?'18 As an extension to this question one might ask whether this will eventually lead to a canon so inclusive that it will no longer serve its purpose. Brzyski (2007) argues that it will be difficult to practise art history without a canon as long as evaluation is part of that practice.

Just as with books, there is a limit to how much physical museum buildings can be extended to encompass more works. In 2019, The Museum of Modern Art in New York, MoMa, reopened after a major renovation and expansion of their galleries. The reconfigured exhibition of their permanent collections is based on a new take on modernism. Film, photography and design objects share space with paintings and non-Western artists have been added. ${ }^{19}$ According to Langfeld (2018: 1), 'the canon of the modern era, as expressed in the collections of large, influential art museums, in textbooks, in market prices for art and so on, is relatively homogenous'. Increasing geographical diversity is one of the measures that art historians are calling for in order to alter the traditional canon (Iskin 2017).

Another display strategy used by museums is rotation. In order to avoid a single narrative of art history, MoMa intends to rotate a third of its collections every six months ${ }^{20}$ The same strategy is deployed by the newly refurbished Nationalmuseum in Stockholm, Sweden, where the Timeline, an exhibition including art, craft and design is arranged in a chronological fashion. ${ }^{21}$ In order to expose as much as possible of the collection, objects are regularly replaced with other objects. However, the decision about which objects to display is still taken by the curators. Participatory practices, involving the public and local communities, have been long-standing within cultural museums (Simon 2010). Participation has also occurred within art museums, but has seldom entailed curatorial projects. One exception is the exhibition gerhardWER? that took place in Gerhard-Marcks-Haus, Bremen, Germany, in 2011, where the exhibition was based on suggestions from visitors (Piontek 2017).

Sanderhoff thinks the time has come for art historians to loosen their grip on the yardstick, which is the literal meaning of canon:

I would like to suggest that museums should let go of the notion that is ip to us to decide which objects are more or less interesting to the public - for aesthetic or educational reasons - and start listening to the grapevine of the Internet where people look for, study, use, discuss, and evaluate art all the time (Sanderhoff 2017: 215)

She takes Wikipedia as an example of a context where artworks are viewed outside the museum domain and from which museums could gain new perspectives on art education. Several institutions with digitized collections have decided to allow users to download high resolution images and make them available under the Public Domain licence, for instance the Rijksmuseum (Amsterdam), the Metropolitan Museum of Art (New York), Nationalmuseum (Sweden) and Statens Museum for Kunst (Copenhagen); the institutions encourage people to share and remix the images. Downloading high resolution images is also a feature of the Arosenius archive. What will happen to the images when they have been downloaded from the platform? Will they be manipulated and formed into collections and displayed in new 
contexts? Arosenius made some paper figures as sketches for The Cat Journey. One could imagine the reverse process - characters from Arosenius' paintings made into paper figures by users, perhaps for children to play with. The high resolution of the digital images makes it possible to discover small details and figures in his paintings, like the spider and the rat on the floor in The Princess at the Troll's. Cartoons could be made with such figures or his other characters, forming new stories, unthought of by the artist, bringing Arosenius' work into the present era.

\section{Conclusion}

When discussing new search and display strategies and methods in the field of art, it is important not to see them solely as technological innovations, but also to examine the ideas on which they are based and their roots in the tradition of art history. In this article, I have shown how current display strategies can be traced back to the thinking of Aby Warburg and André Malraux. I have also pointed to the connection between e-commerce platforms and art museum websites and how the rhetoric of the former has been taken over by the latter.

Returning to the key questions posed in the introduction, what are the possibilities and pitfalls of the three features under discussion? The main advantage of random display is that it opens up a collection for further browsing, without requiring previous knowledge on the part of the visitor. When, as in the case of the Arosenius archive, random display is combined with suggestions based on tags, the visitor can be led in different iconographic directions, which can result in a fruitful exploration of the archive. Random display is also a way to avoid showing the traditional selection of canonical works first. On the negative side, however, placing works side by side in a random order can be confusing and might encourage visitors to make contrived connections between them. Since humans have a tendency to find meaning even in arbitrary constellations, visitors might come to see connections that they would otherwise not have perceived. This kind of serendipity could lead to new insights, but could equally lead visitors astray.

Recommendations are frequently used on commercial websites to guide and encourage customers to further purchases. In art museum websites, recommendations are often based on metadata of objects. This can be a helpful tool for visitors, but when combined with a rhetoric borrowed from e-commerce platforms, in the form of phrases such as 'You might like', one risks getting the impression that museums are marketing art that is likeable. In contrast to the clothing industry and fashion shops, where the categorization of goods is easier, making assumptions about what kind of art a visitor might want to see next is less straightforward. Another pitfall is that recommendations can also contribute to shaping the preferences of visitors and users, as research on the preferences of music consumers has shown (Adomavicius et al. 2019). It is reasonable to believe that this might also apply to art consumers.

An advantage of Al-powered visual similarity search is that it does not rely on language, so that a visitor does not have to enter search terms to navigate a collection. However, visual similarity does not guarantee a meaningful connection between objects. Also somewhat problematic is the underlying assumption that visitors wish to see more of the same, which is not always the case.

Even if novel technologies for display and visualization of art are used, the discourse and rhetoric of traditional art history still resides on the websites of many art museums, promoting the masterpieces of the collections. New technology can be deployed to increase accessibility to collections, but to alter the canon, technology in itself is not enough.

In the case of the Arosenius archive, one of the main ideas behind the platform is to bring together his whole lifework in one space, albeit virtual. During the course of the project, the idea was brought forward that this totality could also be maintained in the physical museums if the institutions that own his work could complement their own holdings with a virtual display of the part of the collection they lack or with works that they own but cannot display. In this way, the whole collection would be accessible in all the different geographical locations, not only on the web platform. This is one example of ideas for further research generated by the project and it will form the basis of a future research application in collaboration with Nationalmuseum. 
The ambition to give visitors access to the whole collection and thereby change the canon is laudable, but is there such a thing as innocent visitors, who can discover something new on their own? Do we still tread in the footsteps of art historians, seeing what we are taught to see? Or does machine learning teach us new ways of seeing, which we will internalize and come to think of as the 'natural' way of seeing in the future? These questions are worth exploring through future research, and to answer them, a transdisciplinary approach would be required.

Received: 9 September 2019 Finally accepted: 6 June 2020

\section{Notes}

1 Mnemosyne Atlas, 'Ten panels from the Mnemosyne Atlas', 2016. https://warburg.library. cornell.edul, accessed 1 August 2019.

2 Lev Manovich, Instagram and Contemporary Image, 2017. http://manovich.net/content/04projects/150-instagram-and-contemporary-image/instagram book manovich_2017.pdf. accessed 1 August 2019.

3 Mitchell Whitelaw, 'Generous Interfaces', conference presentation at EuropeanaTech 2018. https://docs.google.com/presentation/d/1xDOfOHXkZgqkkOD6RJ1qo5YWpgmA Y 4rr2 zXaA39J8/edit\#slide=id.p, accessed 1 August 2019.

4 John Coburn, 'I Don't Know What I'm Looking For: Better Understanding Public Usage and Behaviours with Tyne \& Wear Archives \& Museums Online Collections', MW2016: Museums and the Web 2016. https://mw2016. museumsandtheweb.com/paper/i-dontknow-what-im-looking-for-better-understanding-public-usage-and-behaviours-with-tynewear-archives-museums-online-collections/, accessed 1 August 2019.

5 http://aroseniusarkivet.org/\#/search, accessed 1 August 2019.

6 https://www.nationalgallery.org.uk/paintings/explore-the-paintings/take-a-chance, accessed 1 August 2019.

7 Jonathan Westin, 'Aroseniusarkivet - ett generöst gränssnitt till ett konstnärskap', 23 May 2019. http://www.k-blogg.se/2019/05/23/aroseniusarkivet-ett-generost-granssnitt-till-ettkonstnarsskap/, accessed 13 February 2020.

8 https://www.metmuseum.org/art/collection/search/31153, accessed 1 August 2019. See also Elena Villaespesa and Madhav Tankha, 'The Met's Object Page: Towards a New Synthesis of Scholarship and Storytelling', MW2019: Museums and the Web 2019. https:// mw19.mwconf.org/paper/the-mets-object-page-towards-a-new-synthesis-of-scholarshipand-storytellingl, accessed 13 February 2020.

9 https://www.tate.org.uk/art, accessed 1 August 2019.

10 A major standard is the Europeana Data Model, developed to manage metadata from a diverse range of heritage institutions. It has been adopted by other cultural aggregators, outside Europe. https://joinup.ec.europa.eu/solution/europeana-data-model/about, accessed 13 February 2020

11 https://www.zalando.co.uk/anna-field-trainers-black-an611a0ed-q11.html, accessed 1 August 2019.

12 https://taylorandfrancis.com/, accessed 1 August 2019. https://www.amazon.com/ BlenderBottle-Classic-Shaker-Bottle-20-Ounce/dp/B07YF5C1V2?pf rd p=3e7c82659bb7-5ab2-be71-1af95f06a1ad\&pf rd $r=V Y 8 S 3 K W W P 1 M Z Z 56 Q V E 84 \& p d ~ r d$ $w g=b 3 L A U \& r e f=p d \quad g w$ ri\&pd $r d \_w=S r T q o \& p d \_r d \quad r=28311982-e 54 c-47 d b-a 4 a 5-$ c01aefb069b9, accessed 13 February 2020. 
13 Han S. Lee, Heechul Jung, Alex A. Agarwal and Junmo Kim, 'Can Deep Neural Networks Match the Related Objects?: A Survey on ImageNet-trained Classification Models', arXiv:1709.03806 [cs.CV] 2017. https://arxiv.org/abs/1709.03806, accessed 1 May 2020.

14 Magnus Bognerud, 'Current Digital Collection Management Projects at Nasjonalmuseet', presentation at the 'Art, Collections and Data Across Borders' workshop in Bratislava, 3 August 2016. https://www.slideshare.net/lab SNG/magnus-bognerud-current-digitalcollection-management-projects-at-nasjonalmuseet, accessed 1 August 2019.

15 Been Kim, Emily Reif, Martin Wattenberg and Samy Bengio, 'Do Neural Networks Show Gestalt Phenomena? An Exploration of the Law of Closure', arXiv:1903.01069 [cs.LG] 2019. https://arxiv.org/abs/1903.01069, accessed 1 February 2020.

16 Mario Klingemann and Simo Doury 'X Degrees of Separation', 2018. https://experiments. withgoogle.com/x-degrees-of-separation, accessed 1 August 2019.

17 Although exceptions exist, see Bianchi 2016.

18 John Paoletti, 'The Art History Survey Text: More, More . . .?' caa.reviews 19 May 2006. http://www.caareviews.org/reviews/843, accessed 1 May 2020.

19 Melissa Smith, "We Have to Rethink the Categories': Curators, Scholars, and Artists Discuss MoMA's Attempt to Open Up the Art Historical Canon', 2019. https://news.artnet. com/exhibitions/moma-permanent-galleries-1683286, accessed 1 May 2020.

20 Smith, 'We Have to Rethink the Categories'.

21 Nationalmuseum, 'New Objects in the Timeline'. https://www.nationalmuseum.se/en/nyaf\%C3\%B6rem\%C3\%A5I-i-tidslinjen, accessed 1 August 2019.

\section{References}

Adomavicius, G., Bockstedt, J.C., Curley, S.P., Zhang, J. and Ransbotham, S. (2019) 'The Hidden Side Effects of Recommendation Systems', MIT Sloan Management Review, 60 (2) 13-5.

Ardissono, L., Kuflik, T. and Petrelli, D. (2012) 'Personalization in Cultural Heritage: The Road Travelled and the One Ahead', User Modeling and User-Adapted Interaction, 22 73-99 http://www.di.unito.it/ liliana/EC/UMUAI-CH-12.pdf

Becker, C. (2013) 'Aby Warburg's Pathosformel as Methodological Paradigm', Journal of Art Historiography, 9 CB1-CB25. https://arthistoriography.files.wordpress. com/2013/12/becker.pdf

Bianchi, P. (2016) 'The Random Placement of Art: An Alternative Presentation of the Collection', Studies in Visual Arts and Communication - An International Journal, (3) 2 https://journalonarts.org/wp-content/uploads/2017/01/SVACij Vol3 No2-2016Bianchi-Random-Placement-of-Art.pdf

Brzyski, A. (ed) (2007) Partisan Canons, Durham: Duke University Press.

Finch, M. (2016) 'Dead and Alive: Warburg's Mnemosyne Atlas', Journal of Visual Art Practice, 15 (2-3) 286-97.

Foster, H. (1996) 'The Archive without Museums', October, 77 (110) 97-119. 
Golbeck, J. (2013) 'Social Information Filtering', in Jennifer Golbeck (ed) Analyzing the Social Web, 191-201, Waltham: Morgan Kaufmann/Elsevier.

Herlitz, A. and Westin, J. (2018) 'Assembling Arosenius - Staging a Digital Archive', Museum Management and Curatorship, 33 (5) 447-66.

Iskin, R. (ed) (2017) Re-envisioning the Contemporary Art Canon: Perspectives in a Global World, Abingdon, Oxon: Routledge.

Jing, Y. and Liu, H. (2013) 'A Model for Collaborative Filtering Recommendation in E-commerce Environment', International Journal of Computers, Communications and Control, 8 (4) 560-70.

Kim, H.M., Ghiasi, B., Spear, M., Laskowski, M. and Li, J. (2017) 'Online Serendipity: The Case for Curated Recommender Systems', Business Horizons, 60 (5) 613-620.

Kress, G. and van Leeuwen, T. (1996) Reading Images: The Grammar of Visual Design, London: Routledge.

Langfeld, G., (2018) 'The Canon in Art History: Concepts and Approaches', Journal of Art Historiography, 19 1-18.

Ledin, P. and Machin, D. (2018) Doing Visual Analysis: From Theory to Practice, Thousand Oaks, CA: SAGE Publications.

Malraux, A. (1967) [1947]. Museum Without Walls, trans. Stuart Gilbert and Francis Price. London: Secker \& Warburg.

Manovich, L. (2013) 'Museum Without Walls, Art History Without Names', in Carol Vernallis, Amy Herzog and John Richardson (eds) The Oxford Handbook of Sound and Image in Digital Media, 253-78, New York: Oxford University Press.

(2015) 'Data Science and Digital Art History', International Journal for Digital Art History, 1 12-35.

(2017) 'Cultural Data: Possibilities and Limitations of the Digital Data Universe', in Oliver Grau, Wendy Coones and Viola Rühse (eds) Museum and Archive on the Move. Changing Cultural Institutions in the Digital Era, 259-76, Berlin, Boston: De Gruyter.

Piontek, A. (2017) Museum und Partizipation: Theorie und Praxis kooperativer Ausstellungsprojekte und Beteiligungsangebote, Bielefeld: transcript Verlag

Poljac, E., de-Wit, L. and Wagemans, J. (2012) 'Perceptual Wholes Can Reduce the Conscious Accessibility of Their Parts', Cognition, 123 (2) 308-12.

Sanderhoff, M. (2017) 'The Canon, the Web, and the Long Tail', Journal of Museum Education, 42 (3) 213-23.

Schuller, M. (2011) 'Darstellung des Ungedachten. Zum konstellativen Verfahren in Aby Warburgs Mnemosyne-Atlas', MLN, 126 (3) 581-9.

Simon, N. (2010) The Participatory Museum, Santa Cruz, CA.: Museum 2.0.

Villaespesa, E. (2019) 'Museum Collections and Online Users: Development of a Segmentation Model for the Metropolitan Museum of Art', Visitor Studies, 22 (2) 233-52, DOI:10.1080/10645578.2019.1668679 
Warbelow, A.G. (2013) Camping the Canon: Yasumasa Morimura's Queer Performative Critique of Art History, Ph.D. Thesis, Washington University in St Louis, https:// openscholarship.wustl.edu/art_sci_etds/28

Warburg, A., Warnke, M. and Brink, C. (2000) Der Bilderatlas Mnemosyne, Berlin: Akademie Verlag.

Wertheimer, M. (1938) [1923] 'Laws of Organization in Perceptual Forms', in Willis D. Ellis, A Source Book of Gestalt Psychology, 71-88, London: Routledge \& Kegan Paul.

Westin, J. and Claésson, D. (2017) 'The Painter Is Absent: Ivar Arosenius and the Site-Specific Archaeo-Archival Reconstruction of the Ghost of a Home', Bebyggelsehistorisk Tidskrift, 73 116-29.

Whitelaw, M. (2015) 'Generous Interfaces for Digital Cultural Collections', Digital Humanities Quarterly, (9) 1 http://www.digitalhumanities.org/dhq/ vol/9/1/000205/000205.html

\section{Author}

Karin Wagner is a professor in Art History and Visual Studies at the Department of Cultural Sciences at the University of Gothenburg, Sweden. Her research interests include photography, new media, digital culture, visual communication and packaging design. She is currently involved in the book project From ASCII Art to Comic Sans: Typographic Imagination in Digital Culture.

Professor, Art History and Visual Studies

Department of Cultural Sciences

University of Gothenburg

Sweden

karin.wagner@gu.se 